\title{
Infección reciente del virus del Oeste del Nilo en caballos del oriente de Yucatán, México
}

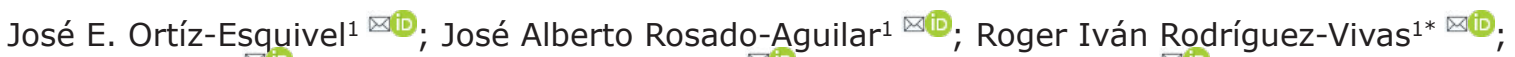

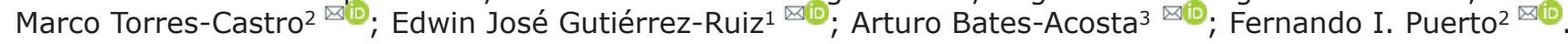 \\ ${ }^{1}$ Universidad Autónoma de Yucatán, Campus de Ciencias Biológicas y Agropecuarias, Facultad de Medicina Veterinaria y \\ Zootecnia, Cuerpo Académico de Salud Animal, km. 15.5 carretera Mérida-X'matkuil, Mérida, México. \\ 2Universidad Autónoma de Yucatán, Campus de Ciencias de la Salud, Centro de Investigaciones Regionales "Dr. Hideyo \\ Noguchi", Laboratorio de Enfermedades Emergentes y Reemergentes, Avenida Itzáes x 59, No. 490, Mérida, México. \\ ${ }^{3}$ Centro de Equinoterapia del Oriente de Yucatán, km. 2 carretera Tizimín-Xkekén, Tizimín, México. \\ *Correspondencia: rvivas@correo.uady.mx
}

Recibido: Agosto 2020; Aceptado: Febrero 2021; Publicado: Mayo 2021.

\section{RESUMEN}

Objetivo. Determinar la circulación del virus del Oeste del Nilo (VON) en caballos del oriente de Yucatán, México. Materiales y métodos. Por conveniencia se estudiaron 184 caballos localizados en 23 unidades de producción de los municipios de Tizimín y Panabá, Yucatán. De cada caballo se obtuvo una muestra de suero sanguíneo, la cual fue evaluada con un ensayo de inmunoabsorción enzimática de captura (MAC-ELISA) para detectar inmunoglobulinas de clase M (IgM) específicas contra VON. Adicionalmente, los sueros seroreactores y los sospechosos fueron analizados con una reacción en cadena de la polimerasa por retrotranscripción (RT-PCR) para detectar ARN viral. Resultados. Ocho caballos estudiados fueron seroreactores en la ELISA-MAC $(4.3 \%, 8 / 184)$ y dos fueron sospechosos $(1.1 \%, 2 / 184)$. Todos estos sueros fueron negativos a la RT-PCR. Conclusiones. La detección de IgM específicas contra VON en los caballos estudiados, demuestra infecciones recientes e indica la circulación del virus en el oriente de Yucatán.

Palabras clave: Anticuerpos; MAC-ELISA; Flavivirus; IgM; serología (Fuente: DeSC).

\section{ABSTRACT}

Objective. To determine the circulation of West Nile virus (WNV) in horses from the eastern Yucatán, Mexico. Materials and Methods. For convenience, 184 horses from 23 production units in the municipalities of Tizimín and Panabá, Yucatán, were studied. A blood serum sample was obtained from each studied horse and evaluated with an immunoglobulin $M$ antibody-capture enzyme-linked immunosorbent assay (MAC-ELISA) to detect immunoglobulin M (IgM) against WNV. Additionally, positive reactor and suspect serum samples were analyzed by reverse transcription polymerase chain reaction (RT-PCR) to detect viral RNA. Results. Eight studied horses were seropositive (4.3\%, $8 / 184)$ to WNV and two were suspects $(1.1 \%, 2 / 184)$. All serum samples were negative by RT-PCR. Conclusions. The detection of IgM specific against WNV in the studied horses shows recent infections with the virus and indicates its circulation in eastern Yucatán, Mexico.

Keywords: Antibodies; MAC-ELISA; Flavivirus; IgM; serology (Source: DeSC).

Como citar (Vancouver).

Ortíz-Esquivel JE, Rosado-Aguilar JA, Rodríguez-Vivas RI, Torres-Castro M, Gutiérrez-Ruiz EJ, Bates-Acosta A, Puerto FI. Infección reciente del virus del Oeste del Nilo en caballos del oriente de Yucatán, México. Rev MVZ Córdoba. 2021; 26(3):e2165. https://doi.org/10.21897/rmvz.2165 


\section{INTRODUCCIÓN}

El virus del Oeste del Nilo (VON), clasificado como un patógeno reemergente en el continente americano por presentar un aumento en su distribución y en el número de infecciones $(1,2)$, es un virus ARN de polaridad positiva, perteneciente al género Flavivirus, que representa un problema de salud pública a nivel mundial $(2,3)$. En el ciclo de transmisión, los mosquitos del género Culex son los vectores biológicos y las aves silvestres son los hospederos amplificadores $(2,4)$.

Los seres humanos y los equinos, incluyendo los caballos domésticos, son hospederos finales y accidentales, por lo que en ellos las manifestaciones de la infección van desde cuadros asintomáticos (leves) hasta encefalitis grave $(2,4)$.

La detección de ARN viral o de inmunoglobulinas de clase $M(\operatorname{Ig} M)$ específicas contra el virus en el suero sanguíneo de hospederos afectados, se emplea para determinar la circulación o infección reciente con VON $(5,6)$, estrategia que ayuda en la prevención de brotes y evita la extensión de las áreas endémicas (7). En este sentido, en las regiones con climas tropicales con poblaciones de mosquitos Culex, son relevantes los caballos domésticos con infecciones recientes porque, en ausencia de programas de vigilancia epidemiológica, actúan como centinelas en el monitoreo del virus y el subsecuente riesgo de transmisión a los seres humanos $(7,8)$.

En México, los primeros reportes de infecciones con VON fueron en aves silvestres y caballos domésticos con encefalitis en Coahuila, Tamaulipas y Chihuahua, durante el verano de $2002(1,9)$; no obstante, en todo el territorio nacional se han reportado un número bajo de casos clínicos en seres humanos y caballos domésticos (1). También se ha logrado la detección y el aislamiento del virus en cuervos y gorriones americanos, capturados en áreas cercanas a la frontera con los Estados Unidos de América (EUA) y el sureste de México $(1,9)$.

En 2003, se informaron por primera vez caballos seroreactores IgG contra VON en el estado de Yucatán (10). Además, Loroño-Pino et al (11) describieron que $15 \%$ de una población estudiada de caballos en el oriente de este mismo estado, presentaron IgG contra VON. Adicionalmente, recientemente, Chaves et al (12) utilizando una prueba de reacción en cadena de la polimerasa por retrotranscripción (RT-PCR por sus siglas en inglés), estimaron una frecuencia de VON de $6-27 \%$ en diferentes familias de aves residentes de Yucatán, indicando la transmisión activa del virus. A pesar de estos estudios, en la región no se han detectado caballos seroreactores a IgM contra el VON, lo cual indicaría la infección reciente en estos animales (12).

El objetivo de este trabajo fue determinar la circulación del VON en caballos del oriente de Yucatán, México.

\section{MATERIALES Y MÉTODOS}

Lugar de estudio. El estudio se realizó en los municipios de Tizimín y Panabá, ubicados en el oriente del estado de Yucatán, México. Ambos municipios presentan explotaciones agropecuarias de extensiones variables que cubren casi la mitad de su superficie (49\%), por lo que predominan zonas de pastizales, cultivos introducidos y ganadería de producción semi-extensiva. Su clima predominante es cálido subhúmedo con lluvias en verano con una temperatura media anual de $26^{\circ} \mathrm{C}$ y precipitación pluvial anual de $1.228 \mathrm{~mm}$ (13).

Tipo de estudio y animales estudiados. Se realizó un estudio observacional descriptivo de tipo transversal, aplicando un muestreo no aleatorio. Se eligieron por conveniencia 184 caballos de 23 unidades de producción (de 7 a 10 animales por unidad). Los caballos fueron considerados sin importar sexo, raza y función zootécnica. Los criterios de inclusión fueron: animales mayores de un año, con buena condición corporal (según la escala de Henneke) y sin antecedentes de inmunización contra VON, lo cual fue verificado con el médico veterinario encargado de la unidad de producción o con el dueño del animal.

Durante el periodo de muestreo, todos los caballos seleccionados fueron evaluados físicamente por el médico veterinario responsable, para identificar signos clínicos asociados a la infección con VON, tales como: fiebre, pérdida de apetito, estupor, debilidad muscular en las extremidades traseras, temblor muscular, irritabilidad, inestabilidad postural y trastornos del movimiento $(4,14)$. Además, por cada caballo se obtuvo el historial clínico, proporcionado por el médico veterinario.

Toma y procesamiento de muestras biológicas. De cada caballo se recolectaron hasta $5 \mathrm{ml}$ de sangre completa mediante punción 
de la vena yugular con aguja $21 \mathrm{G} \times 1.5^{\prime \prime}(0.8$ $\mathrm{mm} \times 38 \mathrm{~mm}$ ) y fueron depositados en un tubo Vacutainer ${ }^{\circledR}$ sin anticoagulante (Becton, Dickinson and Company ${ }^{\circledR}$, Franklin Lakes, NJ, Estados Unidos [EU]), los cuales se conservaron en neveras de plástico con refrigerantes durante su estancia en la unidad de producción y hasta su arribo al laboratorio para su procesamiento posterior.

Cada muestra sanguínea se identificó con un número correspondiente al orden de muestreo. Igualmente, en una base de datos digital se registraron los nombres, edades, sexos y coordenadas geográficas, como parte del control interno de los datos.

Las muestras sanguíneas se trasladaron al Laboratorio de Enfermedades Emergentes y Reemergentes (LEER) del Centro de Investigaciones Regionales "Dr. Hideyo Noguchi" (CIR) de la Universidad Autónoma de Yucatán (UADY). Todas las muestras se centrifugaron a $1,500 \mathrm{~g}$ durante cinco minutos para separar el suero, el cual se colectó y depositó en viales de crio-preservación de $1.5 \mathrm{ml}$ con la información correspondiente al animal. Posteriormente, se congelaron $\mathrm{a}-79^{\circ} \mathrm{C}$ hasta el momento de realizar las pruebas para detectar la infección con VON.

Detección de inmunoglobulinas de clase $M$ (IgM) específicas contra VON, mediante un ensayo de inmunoabsorción enzimática de captura (MAC-ELISA). Los sueros sanguíneos de todos los caballos estudiados fueron analizados [previa dilución a una concentración de 1:400, según lo recomendado por Long et al (15)] con la prueba MAC-ELISA IDEXX IgM WNV Capture ELISA Test $^{\circledR}{ }^{\circledR}$ IDEXX ${ }^{\circledR}$, Westbrook, ME, EU), la cual está basada en la detección cualitativa de anticuerpos de clase IgM contra VON en el suero de equinos infectados. Esta prueba ha reportado una sensibilidad de $91.7 \%$ y una especificidad de $99.2 \%$ (15).

En cada microplaca se utilizaron cuatro pocillos para los controles positivo y negativo incluidos en el kit, y en los 92 restantes se dispensaron por duplicado 46 sueros diluidos con un antígeno inespecífico contra VON (en la fila superior de la microplaca) y con un antígeno recombinante contra VON (en la fila inferior).

Todas las microplacas se observaron a $450 \mathrm{~nm}$ de longitud de onda. En los sueros reactivos, la IgM contra VON queda fijada al revestimiento (capa) de IgM anti-equinas colocado en los pocillos de la microplaca. La intensidad del color es proporcional a la cantidad de anticuerpos presentes en el suero problema. Para determinar los sueros reactivos o sospechosos se calculó el índice de respuesta inmune (ISR por sus siglas en inglés) que es el coeficiente de interpretación entre densidades ópticas. Se consideró como negativo $<2.0$, sospechoso $\geq 2.0-3.0$ y positivo $>3.0$, de acuerdo con escalas establecidas por el fabricante.

\section{Detección de ARN viral por reacción en cadena} de la polimerasa por retrotranscripción (RTPCR). Todos los sueros positivos o sospechosos fueron evaluados por RT-PCR. La extracción de ARN viral en estos se realizó de acuerdo con el protocolo descrito en el kit QIAamp Viral RNA Mini Kit ${ }^{\circledR}$ (QIAGEN ${ }^{\circledR}$, Barcelona, España).

La reacción de transcriptasa reversa (RT por sus siglas en inglés) se llevó a cabo con el protocolo del kit RevertAid H Minus First Strand CDNA Synthesis Kit ${ }^{\circledR}$ (Thermo Fisher Scientific ${ }^{\circledR}$, Waltham, MA, EU), utilizando $5 \mu \mathrm{l}$ de ARN. Las condiciones en el termociclador fueron: alineamiento a $42^{\circ} \mathrm{C}$ durante dos minutos, amplificación a $42^{\circ} \mathrm{C}$ durante 50 minutos y un ciclo adicional a $70^{\circ} \mathrm{C}$ durante 15 minutos para inactivar la enzima.

Para la detección de ARN viral se realizó una PCR punto final, en ella se emplearon los oligonucleótidos descritos por Lanciotti et al (16): sentido 5'-TTGTGTTGGCTCTCTTGGCGTTCTT-3' y antisentido 5'-CAGCCGACAGCACTGGACATTCATA-3', los cuales amplifican un fragmento conservado de 408 pares de bases $(\mathrm{pb})$ ubicado entre los genes de la proteína de la nucleocápside y de la premembrana del VON.

Los reactivos empleados en la reacción tuvieron las siguientes concentraciones finales para un volumen de $25 \mu \mathrm{l}$ : $1 \mathrm{X}$ buffer, $0.2 \mathrm{mM}$ de dNTP's, $2.5 \mathrm{mM}$ de $\mathrm{MgCl}_{2}, 0.4 \mu \mathrm{M}$ de cada cebador, $1 \mathrm{U}$ de Taq polimerasa (Promega ${ }^{\circledR}$, Madison, WI, EUA), 3 $\mu \mathrm{l}$ de ADN complementario (ADNc) y el volumen correspondiente de agua ultra pura. El programa del termociclador fue: desnaturalización inicial a $95^{\circ} \mathrm{C}$ durante cinco minutos, seguido de 40 ciclos (desnaturalización a $95^{\circ} \mathrm{C}$ durante un minuto, alineamiento a $60^{\circ} \mathrm{C}$ durante un minuto, amplificación a $72^{\circ} \mathrm{C}$ durante dos minutos) y una elongación final a $72^{\circ} \mathrm{C}$ durante cinco minutos.

En todas las reacciones se empleó como control positivo ADNc sintetizado a partir de ARN inactivado de VON (contenido en una vacuna 
comercial y obtenido con el protocolo de RT descrito previamente). El control negativo fue una mezcla de todos los reactivos empleados en la reacción, pero sin ADNc. La electroforesis de los productos de PCR se realizó en geles de agarosa al $1.2 \%$ teñidos con bromuro de etidio al $5 \%$. Se utilizó un foto-documentador (Bio-Rad ${ }^{\circledR}$, Hercules, CA, EUA) para el registro de resultados.

\section{RESULTADOS}

Se muestrearon 184 caballos, de los cuales 123 pertenecieron al municipio de Tizimín y 63 al municipio de Panabá.

La MAC-ELISA arrojó ocho (tres de Panabá y cinco de Tizimín) caballos reactores positivos $(4.3 \%, 8 / 184)$ y dos (uno por municipio) como sospechosos (1.1\%, 2/184; Tabla 1$)$. Todos estos sueros resultaron negativos en la RT-PCR. En el historial clínico otorgado por el médico veterinario y en la evaluación física realizada durante el muestreo, no se detectaron signos clínicos asociados a la infección con VON en ningún caballo estudiado.

Tabla 1. Relación de resultados positivos y sospechosos arrojados por la MAC-ELISA realizada a los sueros sanguíneos de caballos estudiados de los municipios de Tizimín y Panabá, Yucatán, México.

\begin{tabular}{|c|c|c|c|c|}
\hline \multirow[b]{2}{*}{ ID } & \multirow{2}{*}{$\begin{array}{l}\text { Municipio de } \\
\text { la unidad de } \\
\text { producción }\end{array}$} & \multicolumn{3}{|c|}{ Resultados MAC-ELISA } \\
\hline & & $\begin{array}{l}\text { Grados de } \\
\text { absorbancia a } \\
\text { Do } 450 \text { nm* }\end{array}$ & $\begin{array}{l}\text { ISR de } \\
\text { ELISA }\end{array}$ & Diagnóstico \\
\hline 95 & Panabá & $\begin{array}{l}\text { WNRA: } 0.68 \\
\text { NCA: } 0.053\end{array}$ & 12.83 & Positivo \\
\hline 147 & Panabá & $\begin{array}{c}\text { WNRA: } 1.055 \\
\text { NCA: } 0.123\end{array}$ & 8.58 & Positivo \\
\hline 90 & Panabá & $\begin{array}{l}\text { WNRA: } 0.281 \\
\text { NCA: } 0.069\end{array}$ & 4.07 & Positivo \\
\hline 49 & Tizimín & $\begin{array}{c}\text { WNRA: } 0.562 \\
\text { NCA: } 0.077\end{array}$ & 7.30 & Positivo \\
\hline 65 & Tizimín & $\begin{array}{c}\text { WNRA: } 0.424 \\
\text { NCA: } 0.068\end{array}$ & 6.24 & Positivo \\
\hline 58 & Tizimín & $\begin{array}{c}\text { WNRA: } 0.374 \\
\text { NCA: } 0.066\end{array}$ & 5.67 & Positivo \\
\hline 168 & Tizimín & $\begin{array}{c}\text { WNRA: } 0.259 \\
\text { NCA: } 0.059\end{array}$ & 4.39 & Positivo \\
\hline 51 & Tizimín & $\begin{array}{c}\text { WNRA: } 0.176 \\
\text { NCA: } 0.053\end{array}$ & 3.32 & Positivo \\
\hline 97 & Panabá & $\begin{array}{c}\text { WNRA: } 0.283 \\
\text { NCA: } 0.119\end{array}$ & 2.38 & Sospechoso \\
\hline 57 & Tizimín & $\begin{array}{c}\text { WNRA: } 0.149 \\
\text { NCA: } 0.06\end{array}$ & 2.48 & Sospechoso \\
\hline
\end{tabular}

ID: identificación del caballo, ISR: índice de respuesta inmune, *densidades ópticas (DO) leídas a $450 \mathrm{~nm}$ para reactivos con WNRA (antígeno recombinante de VON) y con NCA (antígeno inespecífico).

\section{DISCUSIÓN}

Los ocho caballos seroreactores a IgM contra VON de este trabajo representan una frecuencia de $4.3 \%$. Anteriormente, Loroño-Pino et al (10) informaron una frecuencia (obtenida por prueba de neutralización) de anticuerpos IgG contra VON de $1.1 \%(3 / 252)$, en caballos de la zona costera, centro y oriente de Yucatán, siendo de Tizimín más de la mitad de los casos positivos. Asimismo, en otro estudio, Loroño-Pino et al (11) obtuvieron (mediante una ELISA de bloqueo) una frecuencia de anticuerpos IgG de 15\% (28/186) en caballos de municipios del oriente de Yucatán, incluyendo Tizimín y Panabá. La diferencia entre las frecuencias de caballos seroreactores contra VON, identificadas en años distintos, puede deberse a la densidad poblacional (menor o mayor) de caballos susceptibles y no inmunizados en los sitios de estudio, así como por un aumento o disminución en la tasa de introducción del virus por la migración de aves silvestres en el sureste de México (11).

En los trabajos de Loroño-Pino et al $(10,11)$, se demostró la infección con VON en caballos domésticos de Yucatán; sin embargo, estos no indicaron infecciones recientes en los animales afectados. En este contexto, Joó et al (14) señalan que los caballos infectados pueden presentar títulos altos de IgG contra VON hasta los tres años post infección.

Por otra parte, Mattar et al (17) describieron, empleando una prueba ELISA, IgM contra VON en dos de 12 caballos estudiados en Colombia, concluyendo que las infecciones tenían probablemente un curso no mayor de 3 meses. Esta descripción refuerza la evidencia de que los caballos seroreactores identificados en el presente trabajo, presentaban infecciones recientes y que, aunado a los estudios pasados $(10,11)$, la circulación de VON posee una tendencia endémica en este tipo de animales. En este sentido, Pérez-Ruiz et al (5) mencionan que para establecer la circulación del VON en una región particular, es necesaria la detección del agente viral y/o la demostración de IgM específica contra VON en suero sanguíneo o líquido cefalorraquídeo, hallazgos que también sirven para detectar la circulación temprana del virus y evitar la generación de brotes en animales susceptibles o en seres humanos.

En este estudio también se identificaron dos caballos seroreactores sospechosos $(1.1 \%)$, lo cual pudo deberse a que los títulos de IgM en 
estos animales no fueron lo suficientemente altos para alcanzar el punto de corte establecido en la MAC-ELISA y ser considerados positivos. Este hallazgo es habitual en hospederos con infecciones subagudas que se caracterizan por una titulación baja y por presentarse desde los cuatro hasta los diez días posteriores a la exposición inicial al virus $(14,18)$. De igual manera, se ha descrito que la IgM puede persistir en niveles bajos hasta dos meses después de la primera exposición $(14,19)$.

Es importante mencionar que la especificidad de las pruebas ELISA ha mejorado con el implemento de fragmentos de proteínas específicas de VON para diferenciarlo entre los Flavivirus, siendo el más utilizado el dominio (DIII) de la proteína $\mathrm{E}$ que sobresale en la superficie del virus (18). Particularmente, la MAC-ELISA ha sido validada para detectar IgM contra VON en un estudio realizado con caballos de Florida, EU (15), en el cual se concluyó que puede identificar la exposición reciente al virus con una especificidad de $91.7 \%$ y sensibilidad de $99.2 \%$. Este tipo de prueba también ha sido utilizada para detectar caballos seroreactores en regiones endémicas de otros países como Croacia (20), Hungría e Italia (14).

La MAC-ELISA (IDEXX IgM WNV Capture ELISA Test ${ }^{\circledR}$ ) empleada en la presente investigación ha sido evaluada por Joó et al (14), estableciendo una sensibilidad y especificidad de $95 \%$ (tomando la prueba de neutralización como prueba de oro) en una región endémica de VON (Hungría) donde también circulan otros Flavivirus.

Tanto los caballos seroreactores positivos como los sospechosos encontrados por MAC-ELISA fueron negativos a la RT-PCR, lo cual muestra que no tenían una viremia detectable o activa en el momento de la toma de muestra sanguínea. En este sentido, la Organización Mundial de Sanidad Animal (OIE por sus siglas en francés), señala que la viremia en caballos afectados es breve y se produce durante el periodo de incubación de la enfermedad (de 3 a 15 días) después de la transmisión del VON por la picadura del mosquito vector. Durante este tiempo, los anticuerpos son escasos, debido a que se inicia su producción, la cual precede a la aparición de signos clínicos en caso de que se presenten (19).

Los municipios de Tizimín y Panabá tienen una temperatura media anual de $26^{\circ} \mathrm{C}$ y precipitación pluvial anual de 1.228 mm (13). Estas características medioambientales, según lo reportado por la Agencia de Protección Ambiental (EPA por sus siglas en inglés), son las condiciones idóneas para el mantenimiento de poblaciones de mosquitos vectores de VON, sobre todo en zonas selváticas y peridomésticas (21), elementos que influyen en la circulación del virus (1). Otro factor que participa en esta circulación, son las poblaciones de hospederos susceptibles, necesarias para que ocurra una estabilidad enzoótica en las aves silvestres, principales responsables del mantenimiento del ciclo de transmisión $(1,22)$.

La infección en los caballos y en otros hospederos susceptibles como los seres humanos, se produce por el desbordamiento del ciclo enzoótico propio de zonas selváticas de las regiones tropicales (7). Este desbordamiento es favorecido por la proximidad con los mosquitos vectores y con las especies de aves reservorios $(7,21)$. En este contexto, en Yucatán se ha descrito una distribución amplia (en zonas selváticas y peridomésticas) de mosquitos del género Culex (23) que pudieran estar participando en la transmisión de VON.

Por otra parte, según Kilpatrick (24), en algunas regiones de América del Norte, la incidencia de VON en animales susceptibles como los caballos domésticos, aumentará debido a la urbanización y la destrucción de hábitats naturales, ya que se ha demostrado que la distribución del virus está asociada con el uso antropogénico de la tierra y el incremento de las poblaciones de animales domésticos y especies de aves silvestres que toleran a los seres humanos. Estas características pueden influir en la infección con VON de los caballos estudiados, ya que los municipios de Tizimín y Panabá cuentan casi con un $49 \%$ de su superficie destinada para la ganadería y agricultura (13).

En la evaluación física y en el historial clínico de los caballos seroreactores o sospechosos, no se identificaron signos clínicos relacionados con la enfermedad por VON, lo cual indica la presencia de infecciones asintomáticas. En este sentido, la OIE menciona que a nivel mundial la mayoría de las infecciones en caballos domésticos son asintomáticos (19). Debido a esto, se han formulado algunas hipótesis sobre las infecciones asintomáticas en hospederos susceptibles de países con climas tropicales (incluyendo México) a diferencia de los países de Norte América (donde la mayor parte de las infecciones son sintomáticas), siendo una de las más aceptadas la protección cruzada otorgada 
por la infección con otros Flavivirus endémicos (25) y la circulación de cepas atenuadas en virulencia de VON en México $(25,26)$.

Los resultados de esta investigación aportan antecedentes recientes del comportamiento del VON en caballos del oriente de Yucatán. Es necesario realizar más investigaciones para aislar y caracterizar las cepas del virus que infectan a otros hospederos susceptibles y vectores biológicos de la región (27), que permitan describir el riesgo de transmisión, sobre todo, a los habitantes del oriente del estado.

Se concluye que la detección de caballos seroreactores a IgM contra VON, indica infecciones recientes y la circulación del virus en los municipios de Tizimín y Panabá Yucatán, México.

\section{Conflicto de intereses}

Los autores declaran no tener conflicto de interés.

\section{Agradecimientos}

Al Consejo Nacional de Ciencia y Tecnología de México por la beca (No. 448330) otorgada al MVZ. José Emigdio Ortíz Esquivel para la realización de estudios de Maestría en Ciencias Agropecuarias en el Campus de Ciencias Biológicas y Agropecuarias de la Universidad Autónoma de Yucatán. Al personal del Laboratorio de Enfermedades Emergentes y Reemergentes del Centro de Investigaciones Regionales "Dr. Hideyo Noguchi" por su apoyo para la realización de este estudio.

\section{REFERENCIAS}

1. Chancey C, Grinev A, Volkova E, Rios $M$. The global ecology and epidemiology of West Nile Virus. BioMed Res Int. 2015; Article ID: 376230. http://dx.doi. org/10.1155/2015/376230

2. David S, Abraham AM. Epidemiological and clinical aspects on West Nile Virus, a globally emerging pathogen. Infect Dis. 2016; 48(8):571-586. http://dx.doi.org/1 $\underline{0.3109 / 23744235.2016 .1164890}$

3. Al-Jabi SW. Global research trends in West Nile virus from 1943 to 2016: a bibliometric analysis. Global Health. 2017; 13:55. http:// dx.doi.org/10.1186/s12992-017-0284-y

4. Loza-Rubio E, Rojas-Anaya E, López-Ramírez R, Saiz J, Escribano-Romero E. Prevalence of neutralizing antibodies against West Nile Virus (WNV) in monkeys (Ateles geoffroyi and Alouatta pigra) and crocodiles (Crocodylus acutus and $C$. acutus-C. moreletti hybrids) in Mexico. Epidemiol Infect. 2016; 144(11):2371-2373. http:// dx.doi.org/10.1017/S0950268816000790

5. Pérez-Ruiz M, Sanbonmatsu GS, Claverob JMA. Infección por virus West Nile. Enferm Infecc Microbiol Clin. 2011; 29(Supl.5):2126. http://dx.doi.org/10.1016/S0213$\underline{005 \times(11) 70040-4}$
6. García-Ruíz D, Martínez-Guzmán MA, Cárdenas-Vargas A, Marino-Marmolejo E, Gutiérrez-Ortega A, González-Diaz E, et al. Detection of dengue, west Nile virus, rickettsiosis and leptospirosis by a new real-time PCR strategy. Springerplus. 2016; 5(1):671. http://dx.doi.org/10.1186/ s40064-016-2318-y

7. CDC: Centers for Disease Control and Prevention. West Nile Virus in the United States: Guidelines for surveillance, prevention, and control [Internet]. Fort Collins, Colorado, US. 2013. URL disponible en: http://www.cdc.gov/westnile/resources/ pdfs/wnvguidelines.pdf

8. Garcia-Bocanegra I, Arenas-Montes A, Jaen-Tellez A, Napp S, FernandezMorente M, Arenas A. Use of sentinel serosurveillance of mules and donkeys in the monitoring of West Nile virus infection. Vet J. 2012; 194(2):262-264. http://dx.doi. org/10.1016/j.tvjl.2012.04.017

9. Barbachano-Guerrero A, Vásquez-Aguilar $A A$, Aguirre A, Zavala-Norzagaray AA, CarreraGonzalez E, Lafón-Terrazas A, et al. West Nile virus prevalence in wild birds from Mexico. J Wild Dis. 2019; 55(2):425-431. http:// dx.doi.org/10.7589/2018-03-065

10. Loroño-Pino $M$, Blitvich $B$, Farfán-Ale J, Puerto $\mathrm{F}$, Blanco J, Marlenee $\mathrm{N}$, et al. Serologic evidence of West Nile Virus infection in horses, Yucatan State, Mexico. Emerg Infect Dis. 2003; 9(7):857-859. http://dx.doi.org/10.3201/eid0907.030167 
11. Loroño-Pino MA, Farfan-Ale JA, Garcia-Rejon $\mathrm{JE}$, Lin M, Rosado-Paredes E, Puerto FI, et al. Antibodies to influenza and West Nile viruses in horses in Mexico. Vet Rec. 2010; 166(1):2223. http://dx.doi.org/10.1136/vr.b5586

12. Chaves A, Sotomayor-Bonilla J, Monge O, Ramírez A, Galindo F, SarmientoSilva $E$, et al. West Nile virus in resident birds from Yucatan, Mexico. J Wild Dis. 2016; 52(1):159-163. http://dx.doi. org/10.7589/2015-02-046

13. INEGI: Instituto Nacional de Estadística, Geografía e Informática. Anuario estadístico y geográfico de Yucatán. Mérida, Yucatán. 2017. URL disponible en: http://www. datatur.sectur.gob.mx/ITXEF Docs/YUC ANUARIO PDF16.pdf

14. Joó K, Bakonyi T, Szenci O, Sárdi S, Ferenczie $\mathrm{E}$, Barna $M$, et al. Comparison of assays for the detection of West Nile virus antibodies in equine serum after natural infection or vaccination. Vet Immunol Immunopathol. 2017; 183:1-6. http:// dx.doi.org/10.1016/j.vetimm.2016.10.015

15. Long $M T$, Jeter $W$, Hernandez J, Sellon DC, Gosche D, Gillis K, et al. Diagnostic performance of the equine IgM capture ELISA for serodiagnosis of West Nile virus infection. J Vet Intern Med. 2006; 20(3):608613. http://dx.doi.org/10.1892/08916640(2006)20[608:dpotei]2.0.c0;2

16. Lanciotti RS, Kerst AJ, Nasci S, Godsey S, Mitchell J, Savage M, et al. Rapid detection of West Nile virus from human clinical specimens, field-collected mosquitoes, and avian samples by a TaqMan Reverse Transcriptase-PCR Assay. J Clin Microbiol. 2000; 38(11):4066-4071. https://www. ncbi.nlm.nih.gov/pmc/articles/PMC87542/

17. Mattar S, Edwards E, Laguado J, González M, Álvarez J, Komar N. West Nile virus antibodies in Colombian horses. Emerg Infect Dis. 2005; 11(9):1497-1498. http:// dx.doi.org/10.3201/eid1109.050426

18. De Filette M, Ulbert S, Diamond S, Sanders N. Recent progress in West Nile virus diagnosis and vaccination. Vet Res. 2012; 43:16. https:// doi.org/10.1186/1297-9716-43-16

19. OIE: Organización Mundial de Sanidad Animal. Manual de las pruebas de diagnóstico y de las vacunas para los animales terrestres, Fiebre del Nilo Occidental. París, Francia. 2018. URL disponible en: https://www.oie.int/es/ normas/manual-terrestre/acceso-en-linea/
20. Barbić L, Stevanović $\mathrm{V}$, Kovač $\mathrm{S}$, Maltar L, Lohman JI, Vilibić-Cavlek T, et al. West Nile virus serosurveillance in horses in Croatia during the 2012 transmission season. RAD 517. Medical Sciences. 2013; 39:95-104. http://www.id-vet.com/pdfs/pdfs/WNIGM/ doc261.pdf

21. EPA: US Environmental Protection Agency. 2016. Climate Change Indicators: West Nile Virus. United States [Internet]. URL disponible en https://www.epa.gov/climateindicators/climate-change-indicators-westnile-virus

22. Colpitts TM, Conway MJ, Montgomery RR, Fikrig E. West Nile virus: Biology, transmission, and human infection. Clin Microbiol Rev. 2012; 25(4):635-648. http:// dx.doi:10.1128/CMR.00045-12

23. Dzul-Manzanilla $F$, Manrique-Saide $P$, CheMendoza A, Rebollar-Téllez E. Mosquitos de Yucatán. Biodiversidad y desarrollo humano en Yucatán, regionalización socio-productiva y biodiversidad. CICY, PPD-FMAM, CONABIO, SEDUMA: Mérida, Yucatán, México; 2010.

24. Kilpatrick A. Globalization, land use and the invasion of West Nile virus. Science. 2011; 334(6054):323-327. http:// dx.doi:10.1126/science. 1201010

25. Brault A, Langevin SA, Ramey WN, Fang $Y$, Beasley DWC, Barker CM, et al. Reduced avian virulence and viremia of West Nile virus isolates from Mexico and Texas. Am J Trop Med Hyg. 2011; 85(4):758-767. http://dx.doi:10.4269/ajtmh.2011.10-0439

26. Langevin A, Bowen RA., Ramey WN, Sanders TA, Maharaj PD., Fang Y, et al. Envelope and pre-membrane protein structural amino acid mutations mediate diminished avian growth and virulence of a Mexican West Nile virus isolate. J Gen Virol. 2011; 92:2810-2820. https://doi.org/10.1099/vir.0.035535-0

27. Jaramillo M, Peña J, Berrocal L, Komar N, González M, Ariza K, et al. Vigilancia centinela para el virus del oeste del Nilo en culícidos y aves domésticas en el departamento de Córdoba. Rev MVZCórdoba. 2005; 10(2):633-638. https://doi. org/10.21897/rmvz.467 